\title{
The Mackiean Supervenience Challenge
}

\section{Victor Moberger ${ }^{1}$ (D)}

Accepted: 3 March 2019 / Published online: 18 March 2019

(C) The Author(s) 2019

\begin{abstract}
Non-naturalists about normativity hold that there are instantiable normative properties which are metaphysically discontinuous with natural properties. One of the central challenges to nonnaturalism is how to reconcile this discontinuity with the supervenience of the normative on the natural. Drawing on J. L. Mackie's seminal but highly compressed discussion in Ethics: Inventing Right and Wrong (1977), this paper argues that the supervenience challenge as usually conceived is merely a symptom of a more fundamental challenge in the vicinity.
\end{abstract}

Keywords Non-naturalism $\cdot$ Supervenience challenge $\cdot$ Normative explanation $\cdot$ Tristram McPherson · J. L. Mackie

\section{Introduction}

Non-naturalists about normativity hold that there are instantiable normative properties, and that these are sui generis and metaphysically discontinuous with natural properties. At least since the 1970's, with influential writings by Blackburn (1971) and Mackie (1977), there has been a suspicion that this view of normative properties cannot be reconciled with the widely accepted idea that the normative supervenes on the natural, in the sense that there cannot be a normative difference without a natural one. More recently, this suspicion has been brought to the fore of metaethics by an influential paper, in which Tristram McPherson tries to pin down how the supervenience challenge to non-naturalism is best understood (McPherson 2012). The McPhersonian supervenience challenge does not get to the heart of the matter, however. There is a more fundamental challenge in the vicinity, put forward by Mackie in a highly compressed form. My aim in this paper is to formulate a precise version of this Mackiean supervenience challenge. To do this, however, it will prove useful to dwell at some length on McPherson's argument, since it provides materials from which to build the Mackiean argument. It will also make it clear precisely how the Mackiean argument is an improvement.

Victor Moberger

victor.moberger@filosofi.uu.se

1 Uppsala University, Uppsala, Sweden 
The paper is structured as follows. In the next section I give a detailed presentation of McPherson's argument. In Section 3 I adjust the argument in light of non-naturalist defense strategies. Using a refined version of McPherson's argument as a template, in Section 4 I develop the Mackiean argument. In Section 5 I consider a worry about the argument, which also serves to clarify what the Mackiean challenge consists in. Finally, in Section 6 I end the paper with a brief conclusion.

\section{McPherson's Argument}

\subsection{Non-Naturalism and Metaphysical Discontinuity}

As I mentioned above, McPherson's target is non-naturalism about normativity. ${ }^{1}$ The term "non-naturalism" is associated with views in normative semantics, psychology, epistemology, and metaphysics. Here we are concerned with a metaphysical thesis, specifically the nonnaturalist view of normative properties. The term "normative" can be understood broadly, to include properties such as being morally, prudentially, epistemically, or aesthetically good or bad, right or wrong, rational or irrational. Moreover, non-naturalism is a form of normative realism. The term "property" should thus be understood in a non-deflationary sense. Nonnaturalists maintain that there are such properties and that these are sui generis. What does the latter mean?

It can mean many things, but in this context one thing in particular is relevant. According to non-naturalists, normative facts and properties are metaphysically discontinuous with natural facts and properties. Here are some characteristic quotes:

[I reject] the naturalist claim that $[\ldots]$ normative facts are nothing over and above natural ones. Normative facts are just too different from natural ones to be a subset thereof. (Enoch 2011: 4)

$[\mathrm{N}]$ ormative facts are in a separate, distinctive category [...]. [N]ormative and natural facts differ too deeply for any form of Normative Naturalism to succeed. (Parfit 2011: 326)

[W]rongness seems to be a completely different kind of property from, say, weighing 5 pounds. [...] Value properties are radically different from natural properties. (Huemer 2005: 94$)^{2}$

It is not obvious how this metaphysical discontinuity can be captured in precise terms, but the intuitive idea can be illustrated by pointing to properties which are not discontinuous.

A straightforward way for properties to be metaphysically continuous is by being identical. For example, being ten millimeters in length is presumably the very same property as being one centimeter in length, and so "these" properties are maximally continuous.

\footnotetext{
${ }^{1}$ My characterization of non-naturalism in this section is congenial with McPherson's (2012: §1), but somewhat more detailed.

${ }^{2}$ Cf. Mackie (1977: 38): "If there were objective values, then they would be [...] utterly different from anything else in the universe."
} 
Another way for properties to be continuous is by property composition. ${ }^{3}$ It is controversial whether properties have internal structure. But if they do, a complex property is intuitively continuous with its constituents, even though it is not identical to any, or anyone, of them. An example might be the continuity between the properties of being a bachelor and being unmarried.

Yet another way for continuity to obtain is by functional realization. For example, the property of being healthy is shared by many organisms, each with its own unique set of physical properties. Each such set is a way for an organism to be healthy. Perhaps health can be identified with some hugely disjunctive/conjunctive physical property, which includes all possible such ways. That would no doubt secure metaphysical continuity. But even if health should turn out to be a non-physical property, there is an intuitive sense in which it would still be nothing over and above the physical properties that realize it. ${ }^{4}$

Hopefully this gives us a clearer picture of metaphysical continuity, and also of the nonnaturalist claim that normative properties are discontinuous with natural ones. Something should be said about what is meant by "natural properties," however.

In this context natural properties have been characterized in at least three different ways: as (1) empirically accessible $^{5}$; (2) of the same kind as empirically accessible properties ${ }^{6}$; and (3) ascribable by a non-normative vocabulary. ${ }^{7}$ None of these proposals is without problems. For example, the idea that natural properties should be understood as empirically accessible properties is too narrow, since non-naturalists think of normative properties as discontinuous also with various "philosophical" properties - having psychological persistence conditions, for example - which are not empirically accessible in any interesting sense. I will not try to sort out how non-naturalism should be further precisified, however. I trust that we understand the view well enough for my purposes below. ${ }^{8}$

\subsection{Supervenience and Brute Necessity}

It is widely agreed that the normative supervenes on the natural. In slogan form the idea is that there cannot be a normative difference without a natural one, which leaves room for several different precisifications. The supervenience thesis that is relevant here precisifies the modality in question as metaphysical, which should be distinguished from logical, conceptual, and nomological modality. Let us call the thesis SUPERVENIENCE (following McPherson). Here are two equivalent formulations:

It is metaphysically impossible that: $x$ and $y$ differ in some normative respects, but not in any natural respects.

\footnotetext{
3 See Schroeder (2007: ch. 4) for discussion.

${ }^{4}$ Another example is the relation between determinables and determinates. Redness is in some sense inherent in more specific shades such as scarlet and crimson. Yet another, and more controversial, example is what we might call essential involvement. The idea is that it is part of the very nature, or essence, of certain properties that their instantiation is necessary and/or sufficient for the instantiation of certain other properties. This would render these properties continuous, even though they do not stand in any of the other mentioned continuity-relations (identity, composition, realization, determinable-determinate).

${ }^{5}$ Shafer-Landau (2003: 59).

${ }^{6}$ Enoch (2011: 103).

7 Jackson (1998: 121), Huemer (2005: 66), and Parfit (2011: 305).

${ }^{8} \mathrm{I}$ discuss the issue at greater length in Moberger (2018: 56-63).
} 
It is metaphysically necessary that: if $x$ and $y$ are identical in all natural respects, then they are identical also in all normative respects. ${ }^{9}$

SUPERVENIENCE conjoined with the non-naturalist view of normative properties implies that there are metaphysically necessary connections between discontinuous properties. McPherson further maintains that non-naturalists cannot explain these connections. (Let us call this claim NO EXPLANATION.) There is no mystery concerning how there can be metaphysically necessary connections between being one centimeter and being ten millimeters, being a bachelor and being unmarried, being scarlet and being red, or between certain physical properties and health, since these are metaphysically continuous. No such broadly speaking reductive explanation is available to non-naturalists, however. McPherson further maintains that no other satisfactory explanation is available. If this is right, non-naturalists are committed to brute metaphysically necessary connections between discontinuous properties. And according to a principle that McPherson calls MODEST HUMEAN, this counts significantly against their view.

\subsection{Modest Humean}

Humean skepticism about metaphysical necessity takes many different forms. MODEST HUMEAN is designed to be modest enough to have wide appeal. According to McPherson, the idea that there is a strong presumption against theories which posit the relevant connections "rests fundamentally on powerful methodological intuitions in metaphysics" (2012: 230), and he thinks of its acceptance as a matter of basic metaphysical hygiene.

The principle is however ambiguous in ways that McPherson does not address. First, that something counts against a view could mean either that it provides reason not to accept the view, or that it provides reason to deny it. To illustrate, there is conclusive reason not to accept the view that the number of stars in the Milky Way is even, but there is equally conclusive reason not to deny it. I will assume that what McPherson has in mind with the phrase "counts significantly against" is the stronger reading, on which it means "provides strong reason to deny."

There is a further ambiguity. Does the term "connection" signify any kind of relation at least as strong as correlation, or does McPherson have only correlations in mind? I will assume that MODEST HUMEAN is concerned with any relation that implies correlation. Without this assumption the argument becomes much too easy to evade. This will become clear later on.

Here, then, are the components of McPherson's argument:

SUI GENERIS: If non-naturalism is true, then there are instantiable sui generis normative properties.

${ }^{9}$ These formulations are a bit simplified. Here is a more precise formulation:

For any metaphysically possible worlds $w$ and $w^{*}$ and for any objects $x$ in $w$ and $y$ in $w^{*}$, if $x$ in $w$ and $y$ in $w^{*}$ are identical in all natural respects (including relational ones), then $x$ in $w$ and $y$ in $w^{*}$ are identical in all normative respects.

I prefer to think of $x$ and $y$ as individual objects, such as particular actions or mental states, whereas McPherson (2012: 214) thinks of them as whole possible worlds. This makes no difference to the argument, since the supervenience theses in question are equivalent (at least if we make certain auxiliary assumptions and restrictions which are innocent in this context). See McLaughlin and Bennett (2018: §4.3). 
SUPERVENIENCE: It is metaphysically necessary that: if $x$ and $y$ are identical in all natural respects, then they are identical also in all normative respects.

NO EXPLANATION: Non-naturalists cannot explain SUPERVENIENCE.

MODEST HUMEAN: Commitment to brute metaphysically necessary relations between discontinuous properties provides strong reason to deny a view.

The conclusion is that there is strong reason to deny non-naturalism, other things being equal. $^{10}$

Three defensive strategies are here available to non-naturalists. While they cannot deny sUI GENERIS (since that would amount to abandoning their view), they might deny SUPERVENIENCE, NO EXPLANATION, or MODEST HUMEAN. In the following section I discuss these strategies in turn, with an eye to refining the argument.

\section{Non-Naturalist Defense Strategies}

\subsection{Denying Supervenience}

Could non-naturalists simply deny SUPERVENIENCE? That would be very convenient, since it would render both McPherson's argument and the Mackiean argument that I will develop later unsound. ${ }^{11}$ However, given my aims in this paper I don't feel I need to defend something as fundamental in the present context as SUPERVENIENCE. If SUPERVENIENCE is false, then there is no supervenience challenge to non-naturalism of course, but it is still interesting to see how the challenge might be developed assuming SUPERVENIENCE is true. Thus, if you deny SUPERVENIENCE you can regard the conclusions of this paper as conditional. $^{12}$

\subsection{Explaining Supervenience}

Could non-naturalists instead explain SUPERVENIENCE, thereby evading MODEST HUMEAN? In this section I discuss two possible explanatory strategies: the conceptual strategy and the metaphysical strategy. ${ }^{13}$

\subsubsection{The Conceptual Strategy}

The conceptual strategy makes two claims: (i) that SUPERVENIENCE is a conceptual truth, and (ii) that this explains why it is true. Both of these claims are controversial. Enoch (2011: 148-149) and Olson (2014: 89-90) argue for (i) on the grounds that if someone were to use normative language in a way that takes no notice of SUPERVENIENCE, we would

\footnotetext{
${ }^{10}$ This informal reconstruction roughly parallels McPherson's (2012: §3).

${ }^{11}$ For doubts about SUPERVENIENCE, see Hattiangadi (2018) and Rosen (forthcoming).

${ }_{12}$ Most non-naturalists are in any case not prepared to deny SUPERVENIENCE in order to save their view. For example, David Enoch writes that denying SUPERVENIENCE "would amount to a devastating loss of plausibility points" (2011: 142).

${ }^{13}$ This terminology is from Väyrynen (2017).
} 
regard that person as less than competent with normative terms. It could be questioned whether this is true, however, and also whether it suffices for conceptual-truth status. McPherson does not address (i). His response to the conceptual strategy consists rather in rejecting (ii) on the grounds that conceptual truths quite generally lack the requisite explanatory power (2012: 221-222). ${ }^{14}$

These issues are not pertinent, however, since both (i) and (ii) can be circumvented by switching to a slightly different explanandum:

NECESSITATION: There is some instantiable natural property A, and some instantiable sui generis normative property $\mathrm{B}$, such that it is metaphysically necessary that: if $x$ has A, then $x$ also has B.

Just like SUPERVENIENCE, NECESSITATION involves a metaphysically necessary relation, thus potentially falling prey to MODEST HUMEAN. And insofar as non-naturalists are committed to SUPERVENIENCE, they are committed to NECESSITATION as well. This is because NECESSITATION follows from SUPERVENIENCE conjoined with the non-naturalist claim that there are instantiable sui generis normative properties. And while it is controversial whether the conceptual strategy can be made to work when applied to SUPERVENIENCE, it is clear that no such strategy will work here. This is because NECESSITATION, unlike SUPERVENIENCE, implies the non-naturalist thesis that there are instantiable sui generis normative properties. Hence, if NECESSITATION were a conceptual truth, then non-naturalism itself would be a conceptual truth, which it presumably is not. ${ }^{15}$

I conclude that the conceptual strategy is of no help to non-naturalists. Although it may answer McPherson's argument as stated, there is another version of the argument which is not similarly vulnerable:

DISCONTINUITY: If non-naturalism is true, then NECESSITATION is true. ${ }^{16}$

NO EXPLANATION*: Non-naturalists cannot explain NECESSITATION.

MODEST HUMEAN: Commitment to brute metaphysically necessary relations between discontinuous properties provides strong reason to deny a view.

The conceptual strategy is a non-starter with respect to this argument, since NECESSITATION is not a conceptual truth. ${ }^{17}$

\footnotetext{
${ }^{14}$ See also Väyrynen (2017: 175-176).

15 This objection to the conceptual strategy is closely related to Väyrynen's point that the strategy "explains the wrong necessity" (2017: 176). Note that neither Enoch nor Olson suggests that NECESSITATION can be given a conceptual explanation.

${ }^{16}$ DISCONTINUITY follows from SUI GENERIS conjoined with SUPERVENIENCE.

${ }^{17}$ Supposing SUPERVENIENCE can be explained as a conceptual truth, couldn't non-naturalists explain NECESSITATION simply by pointing out that NECESSITATION follows from SUPERVENIENCE in conjunction with their view? No Wonder NECESSITATION is true if SUPERVENIENCE is true and there are instantiable sui generis normative properties! From a MODEST HUMEAN point of view, however, this is the wrong kind of explanation. While it would tell us why we are committed to NECESSITATION assuming SUPERVENIENCE and non-naturalism, it would not tell us why, metaphysically speaking, the modal relation stated by NECESSITATION holds.
} 


\subsubsection{The Metaphysical Strategy}

Could NECESSITATION instead be given a metaphysical explanation? As I mentioned earlier, nonnaturalists cannot appeal to property identity, property composition, functional realization, or any other kind of metaphysical intimacy. Instead they need to invoke a relation that can hold between discontinuous properties.

The relation must also hold with metaphysical necessity, as it is hard to see how a contingent relation could metaphysically explain a necessary one. But if this is right, the metaphysical strategy is doomed from the start. The relation appealed to, whatever it is, will relate discontinuous properties with metaphysical necessity, and so the problem will just reappear. The point is not that NECESSITATION cannot be explained this way, but rather that no such explanation will circumvent MODEST HUMEAN. ${ }^{18}$ Again, even if the metaphysical strategy should answer McPherson's argument as stated, there is another argument nearby on which it gets no purchase:

DISCONTINUITY: If non-naturalism is true, then NECESSITATION is true.

NO EXPLANATION**: Non-naturalists cannot explain NECESSITATION without committing to a brute metaphysically necessary relation between discontinuous properties. ${ }^{19}$

MODEST HUMEAN: Commitment to brute metaphysically necessary relations between discontinuous properties provides strong reason to deny a view.

If NO EXPLANATION** is true, non-naturalists have no choice but to confront MODEST HUMEAN head-on.

\subsection{Denying Modest Humean}

The upshot of the discussion so far is that non-naturalists are committed to a brute metaphysically necessary relation between discontinuous properties, either in the form of NECESSITATION, or in the form of some other relation, which ultimately explains NECESSITATION. Thus, nonnaturalists need to address MODEST HUMEAN.

As I mentioned above, McPherson thinks MODEST HUMEAN rests on solid intuitive foundations. However, I don't think he accurately pinpoints what it is that makes the principle intuitively compelling (if indeed it is). He writes:

What MODEST HUMEAN denies is that we are permitted, in metaphysical theory construction, to embrace brute necessary connections whenever they appear to be otherwise

\footnotetext{
${ }^{18}$ Leary (2017) suggests that non-naturalists can indeed steer clear of MODEST HUMEAN by appealing to "hybrid properties," whose essences bridge the gap between the natural and the sui generis normative in a way that is consistent with non-naturalism, and without themselves being metaphysically necessary. I have argued elsewhere that Leary's suggestion fails in both these respects. See Moberger (2018: 71-72).

${ }^{19}$ This modification is implicit in McPherson's discussion (2012: 222-223). Cf. Schroeder (2007: 198, n. 1). We can now see why, as I maintained earlier, MODEST HUMEAN must be concerned with any kind of relation at least as strong as correlation. By positing a necessary explanatory relation, non-naturalists will no longer be committed to any brute necessary correlation between discontinuous properties. Hence, unless MODEST HUMEAN can also target the explanatory relation in question, the argument becomes far too easy to evade.
} 
convenient posits. This is close to simply being a characteristic mark of taking the metaphysical project seriously. (2012: 230)

Here the principle is portrayed as both more and as less modest than it really is. Note first the phrase "brute necessary connections." One might think that McPherson is using it casually, as mere shorthand for the cumbersome phrase "brute metaphysically necessary connections between discontinuous properties." It is not clear that this is the case, however. Sometimes one gets the impression that what fundamentally concerns him is brute necessity as such. ${ }^{20}$

This would in any case result in a far from modest principle. There cannot be any presumption against embracing brute necessary relations as such. Why, for example, is water identical to $\mathrm{H}_{2} \mathrm{O}$, and necessarily so? That's just the way the world has to be! Moreover, there cannot be any presumption against embracing brute necessary relations even between numerically distinct properties. Why, for example, does being a bachelor necessarily involve being unmarried (if indeed it does), and why is health necessarily realized by certain physical properties? Again that's just the way the world has to be. The idea that commitment to such brute necessary relations counts against a view is thus anything but intuitive. (And it would be just as hostile to naturalist views, by the way.) Hence, insofar as MODEST HUMEAn is intuitive (and modest), it must be because there is a worry specifically about brute necessary relations between discontinuous properties.

In another respect the principle is however less modest than McPherson makes it appear. What MODEST HUMEAN says, or should say, is not just that we mustn't embrace the relevant relations whenever they appear convenient, but also that we should deny their existence whenever they appear less than obligatory. As I mentioned earlier, it is not sufficient to prohibit the positing of the relevant relations, since that does not rule out that we should suspend judgment about their existence. MODEST HUMEAN should also require that the relations be denied.

Another factor which bears on the principle's modesty and plausibility is the strength of the intended presumption. The principle becomes more plausible, but also less interesting, the weaker compensating reasons non-naturalists are asked to provide. To avoid becoming overly modest, the principle should ask for strong compensating reasons. $^{21}$

So, are we plausibly required to deny the existence of brute metaphysically necessary relations between discontinuous properties, unless strong compensating reasons say otherwise? For present purposes I can remain neutral on this issue. Instead I will show that MODEST HUMEAN is unnecessarily committal. The Mackiean argument that I will develop below appeals to a yet more modest principle. Beyond that, I will suggest that the Mackiean argument gets to the heart of the matter in a way that McPherson's argument does not.

\footnotetext{
${ }^{20}$ See especially his discussion of mathematical Platonism as a potential partner in guilt (2012: 229). Cf. Schroeder (2007: 198).

${ }^{21}$ This is also the way McPherson construes it. See especially his discussion about whether non-naturalists might get away with accepting a burden, but denying that it is particularly weighty (2012: 230-231).
} 


\section{The Mackiean Argument}

\subsection{Necessary Making and Modest Mackiean}

Mackie's main objection to non-naturalism is that sui generis normativity as such is metaphysically bizarre (1977: 38-42). But he also gives another argument, which is more reminiscent of McPherson's:

What is the connection between the natural fact that an action is a piece of deliberate cruelty - say, causing pain just for fun - and the moral fact that it is wrong? It cannot be an entailment, a logical or semantic necessity. Yet it is not merely that the two features occur together. The wrongness must somehow be 'consequential' or 'supervenient'; it is wrong because it is a piece of deliberate cruelty. But just what in the world is signified by this 'because'? (1977: 41)

Even though Mackie here uses the term "supervenient," it is not the thesis I have called SUPERVENIENCE he has in mind. The claim is not (just) that there cannot be a moral or normative difference without a natural one. Nor is it (just) that natural properties would necessitate sui generis normative ones. As he puts it, "it is not merely that the two features occur together." SUPERVENIENCE and NECESSITATION are modal claims. What Mackie has in mind is rather an explanatory claim. Non-naturalists need to assume that actions have sui generis normative properties because they have natural ones.

It is notable that Mackie does not provide any argument for ascribing this commitment to non-naturalists. He just asserts that normative facts and properties "must somehow" be explained by natural facts and properties. Similarly, in another context he writes:

If a state of affairs is good or bad, there must be something about it that makes it good or bad, and similarly there must be something other than its rightness or wrongness that makes an action right or wrong. (1982: 115)

Here Mackie is relying on what Väyrynen (2013) calls "the dependence intuition," which underpins the highly plausible claim that individual objects such as actions, mental states, or institutions have normative properties only insofar as something about those objects makes it so. ${ }^{22}$ Let us call this claim NORMATIVE EXPLANATION:

NORMATIVE EXPLANATION: If $x$ has some normative property $\mathrm{B}$, then $x$ has some natural property A such that $x$ has B because $x$ has A.

This claim is intuitively more basic than SUPERVENIENCE. I doubt that we have any intuitions about the latter independently of the former. Thus, insofar as non-naturalists are committed to SUPERVENIENCE and NECESSITATION, they are committed also to the following thesis:

${ }^{22}$ See also Olson (2014: 89). 
NECESSARY MAKING: There is some instantiable natural property A, and some instantiable sui generis normative property $\mathrm{B}$, such that it is metaphysically necessary that: if $x$ has

$\mathrm{A}$, then $x$ also has $\mathrm{B}$, and because $\mathrm{x}$ has $\mathrm{A}$.

But what in the world is this because-relation? We know that it is supposed to be a metaphysically explanatory relation, not just a modal one. We also know that the relation cannot be even broadly speaking reductive. For obvious reasons, as Mackie notes, it cannot be a logical or analytic entailment-relation either. Nor is it a causal relation.

To this we can add some formal properties. Unlike metaphysical necessitation, the relation would have to be both hyperintensional and non-monotonic. It would have to be hyperintensional since substituting necessarily co-extensive properties is not always truth preserving in normative explanations. To illustrate, even if divine commands were necessarily co-extensive with happiness-maximization, we would still think of utilitarianism and divine command theory as incompatible views in normative ethics. And the relation would have to be non-monotonic since the view that $\mathrm{A}$ makes actions right does not imply the view that $\mathrm{A}$ and $\mathrm{B}$ together make actions right. For example, the view that happiness-maximization together with divine commands make actions right is a rival of both utilitarianism and divine command theory. Also, since the relation is supposed to be explanatory, presumably it would have to be both irreflexive and asymmetric. Whether the relation is also (non-trivially) transitive will however depend on whether it is unique to the normative case, or whether it is a special case of a generic metaphysical grounding-relation. ${ }^{23}$ Grounding is usually taken to be transitive, but this could not apply to a relation which holds only between natural properties and sui generis normative ones. If natural properties are never on the explanandum side of the relation, while sui generis normative properties are never on the explanans side, then there are no chaining cases (A explains B, B explains C) with which to examine whether transitivity, non-transitivity, or anti-transitivity holds.

This gives us a somewhat better grip on the relevant relation. Nevertheless, it still appears less than transparent. It is easy to get an intuitive sense of how being scarlet necessarily makes an object red, for example, or how certain physical properties necessarily make an organism healthy. Such reductive explanatory relations appear intuitively accessible in a way that the non-naturalist's because-relation does not. ${ }^{24}$

Thus, non-naturalists are committed to a metaphysically opaque, virtus dormitiva kind of explanatory relation - a "mysterious consequential link," as Mackie puts it (1977: 41). This suggests the following principle:

MODEST MACKIEAN: Commitment to brute metaphysically necessary explanatory relations between discontinuous properties provides strong reason to deny a view. ${ }^{25}$

\footnotetext{
${ }^{23}$ Metaphysical grounding has received a lot of attention recently. For an overview, see Bliss and Trogdon (2014).

${ }^{24}$ It is not obvious to me that brute contingent explanatory relations between discontinuous properties are any less mysterious than brute necessary ones. Thus, a Mackiean challenge to non-naturalism may remain even if SUPERVENIENCE can be denied. I will not pursue this issue further here, however.

${ }^{25}$ I take it that, strictly speaking, metaphysically explanatory relations hold between facts. The properties themselves are explanatorily connected only in an attenuated sense. For ease of exposition, however, I will continue to speak of explanatory relations holding between properties.
} 
MODEST MACKIEAN targets only a subset of the relations targeted by MODEST HUMEAN. MODEST MACKIEAN is thus logically weaker than MODEST HUMEAN and inherits whatever plausibility attaches to the latter. Logical weakening does not necessarily constitute progress, since in some cases the plausibility of the weaker claim is wholly dependent on that of the stronger. This is not such a case, however, since, as we have seen, MODEST MACKIEAN can avail itself of an additional source of intuitive support (I will return to this claim in Section 5 below).

\subsection{The Argument Stated}

Since I will use the modified version of McPherson's argument as a template, let me restate it before I present the Mackiean argument:

DISCONTINUITY: If non-naturalism is true, then NECESSITATION is true.

NO EXPLANATION**: Non-naturalists cannot explain NECESSITATION without committing to a brute metaphysically necessary relation between discontinuous properties.

MODEST HUMEAN: Commitment to brute metaphysically necessary relations between discontinuous properties provides strong reason to deny a view.

We can now construct the Mackiean argument as follows:

DISCONTINUITY*: If non-naturalism is true, then NECESSARY MAKING is true.

NO EXPLANATION***: Non-naturalists cannot explain NECESSARY MAKING without committing to a brute metaphysically necessary explanatory relation between discontinuous properties.

MODEST MACKIEAN: Commitment to brute metaphysically necessary explanatory relations between discontinuous properties provides strong reason to deny a view.

Due to the common intuitive source of SUPERVENIENCE, NECESSITATION and NECESSARY MAKING, the McPhersonian Discontinuity and the Mackiean DiscontinUity* stand and fall together. And MODEST MACKIEAN is more plausible than MODEST HUMEAN, since it is logically weaker and enjoys additional intuitive support. But what about nO EXPLANATION***? Perhaps it is more vulnerable than its McPhersonian counterpart?

I argued above that NO EXPLANATION** is true, since it is hard to see how a metaphysically necessary relation between $\mathrm{A}$ and $\mathrm{B}$ might be explained without appealing to another metaphysically necessary relation between $\mathrm{A}$ and $\mathrm{B}$. Analogous reasoning supports NO EXPLANATION $^{* * *}$ as well. How, after all, could a metaphysically necessary explanatory relation between $\mathrm{A}$ and $\mathrm{B}$ be explained without appealing to another such relation? Again, the relation would have to be metaphysically necessary. And to metaphysically explain something it would have to be a metaphysically explanatory relation. Sooner or later, then, a brute metaphysically necessary explanatory relation must be invoked.

Since MODEST MACKIEAN is more plausible than MODEST HUMEAN, and since the two arguments are otherwise on a par, the Mackiean argument presents a tougher challenge for non- 
naturalists. Put another way, the Mackiean argument exploits an opportunity that McPherson's argument misses. Assuming SUPERVENIENCE is true, non-naturalists are committed not just to a brute necessary relation between discontinuous properties, but to an explanatory such relation, and so the challenge to non-naturalism can rely on weaker assumptions, as reflected in MODEST MACKIEAN.

Furthermore, the Mackiean argument points our attention to where it should be. The core issue in this area is not how to explain SUPERVENIENCE and NECESSITATION in order to evade MODEST HUMEAN, but how to account for NORMATIVE EXPLANATION. If non-naturalists can do that, they will get an explanation of SUPERVENIENCE and NECESSITATION for free. And if they cannot do that, then MODEST HUMEAN will be the least of their problems. This is because the need to account for NORMATIVE EXPLANATION presents a far more compelling reason why SUPERVENIENCE and NECESSITATION could not be taken to be brute.

\section{The Nomological Model}

In this section I address a worry about the Mackiean argument. This will also serve to clarify what the Mackiean challenge consists in.

I have maintained that the intuitive support for MODEST MACKIEAN is twofold. First, since MODEST MACKIEAN follows from MODEST HUMEAN, whatever intuitions support the latter also support the former. Secondly, MODEST MACKIEAN gains additional support from the Mackiean intuition concerning mysterious consequential links. Or does it?

It might be objected that this intuitive support hinges on a controversial implicit assumption. If the idea is that natural properties (or facts) are supposed to fully explain sui generis normative properties (or facts), then we can all agree that non-naturalists are committed to a mysterious explanatory relation, at least if the relation is taken as brute. But there is a further possibility. On another model, sui generis normative properties are only partially explained by natural properties. The full metaphysical explanation also appeals to a normative law (the content of which can be spelled out in different ways, as we will see shortly). On this nomological model, the explanatory relation referred to in NORMATIVE EXPLANATION can be identified with the partially explanatory relation holding between certain natural and sui generis normative properties, which constitutes only one half of the full metaphysical explanation. And this partially explanatory relation may not appear mysterious at all once we see the whole picture. $^{26}$

MODEST MACKIEAN should thus be distinguished from the following principle:

MODEST MACKIEAN*: Commitment to brute metaphysically necessary fully explanatory relations between discontinuous properties provides strong reason to deny a view.

Consequently, there are two different versions of the Mackiean argument, one employing MODEST MACKIEAN as before, and the other employing MODEST MACKIEAN* (with corresponding

\footnotetext{
${ }^{26}$ McPherson (2012: 220-221) argues that the nomological model is not available to non-naturalists, since on their non-deflationary account of normative properties, normative principles will be explained by the distribution of those properties, rather than the other way round. If this is right, then all the better. I will however proceed on the assumption that this objection fails.
} 
adjustments to the other premises). Perhaps it is only by equivocating on these two arguments that the Mackiean challenge appears to enjoy additional intuitive support. And without such support the challenge becomes superfluous to the case against non-naturalism.

In response, I want to argue that there is no need for equivocation. MODEST MACKIEAN can be understood as MODEST MACKIEAN*. I will proceed as follows. In Sections 5.1 and 5.2 I discuss two different ways of construing the normative laws, both of which promise demystification, but are found to be problematic on independent grounds. In Section 5.3 I discuss a third approach, which avoids the problems that beset the first two, but only by gift-wrapping the mystery.

I cannot rule out that there is some other way of spelling out the nomological model so as to avoid these problems. But this tells us where the challenge lies. The challenge for non-naturalism presented by the Mackiean argument is to show either (1) that NORMATIVE EXPLANATION can indeed be accommodated without mysterious commitments, or (2) that non-naturalism is supported by reasons strong enough to compensate for such commitments. My concern in this section is not to show that non-naturalists cannot take the first of these routes. The point is rather that there is a real challenge here.

\subsection{The Modal Approach}

Rosen (2017) suggests that non-naturalists might construe the normative laws in purely modal terms, in the form of necessary universal generalizations. The notion of necessity involved here is not metaphysical necessity, but a weaker notion of normative necessity, defined in counterfactual terms (2017: §5). Since I have assumed that normative properties supervene on natural properties with metaphysical necessity, however, I need to depart from Rosen's characterization in this regard. I will thus take the idea to be that whenever a particular act has some sui generis normative property B, this is metaphysically explained by the act's having some natural property A, and it being metaphysically necessary that all A-acts are Bacts.

This approach would appear to demystify the non-naturalist's because-relation. While it is mysterious how natural properties could single-handedly explain sui generis normative properties, it does not seem so mysterious how they could explain them if aided by a Rosen-style law.

The modal approach fails, however. First, it is just implausible on the face of it. As Berker (2018: 9) puts it,

we don't generally think that one can explain why some object has some property by citing another property of that object and then pointing out that the second property necessitates the first $[\ldots]$; mere necessitation is the wrong sort of relation to underwrite explanation.

But if this doesn't convince, a more serious problem is that a purely modal account of the normative laws is too coarse-grained to accommodate the formal properties mentioned in Section 4.1 above. Consider hyperintensionality and non-monotonicity first. Suppose the following is a true principle:

MODAL UTILITARIANISM: Necessarily, all happiness-maximizing acts are right. 
If so, then for any distinct natural property A which is necessarily co-extensive with happiness-maximization (perhaps the property of being divinely commanded or maximizing certain quantifiable brain-states, or some infinitely disjunctive/conjunctive physical property), we will get a further true principle:

A-ISM: Necessarily, all A-acts are right.

Furthermore, if MODAL UTILITARIANISM is true, then so is the following principle:

TUESDAYISM: Necessarily, all happiness-maximizing acts performed on a Tuesday are right.

Now, the utilitarianism of normative ethics does imply that A-ISM and TUESDAYISM are true as far as they go, but it does not imply that A or happiness-maximizing on a Tuesday are rightmaking properties. But how can this be accommodated on Rosen's account of the laws? If rightness is explained by happiness-maximization together with MODAL UTILITARIANISM, then why is it not also explained by A together with A-ISM, or by Tuesday-happiness-maximizing together with TUESDAYISM?

Rosen is of course aware of these issues, and he suggests that the genuine laws could be demarcated in one of two ways: non-naturalists could maintain that it lies in the nature, or essence, of the sui generis normative properties that only certain natural properties could figure in the laws (2017: §8); alternatively, non-naturalists could maintain that only fundamental principles qualify as laws (2017: §9). TUESDAYISM, for example, is not fundamental, since it is metaphysically explained by MODAL UTILITARIANISM.

The first suggestion goes against the spirit, if not the letter, of non-naturalism. Given that normative properties are sui generis, it would be surprising indeed if they came with a list of potentially right-making natural properties built into their essence. Furthermore, while the suggestion fits with Rosen's idea that right-making properties differ across metaphysically possible worlds, it is not clear what the distinction between actual and potential right-makers might consist in if, as I have assumed, right-making properties do not differ across worlds. In any case the suggestion is ad hoc, as it is motivated solely by the need to demarcate the laws. Rosen acknowledges this; indeed, it is what motivates the second suggestion. But the second suggestion does not solve the problem. While TUESDAYISM and the like are indeed nonfundamental, A-ISM need not be. Indeed, A-ISM might be more fundamental than MODAL UTILITARIANISM.

Consider asymmetry next. If happiness-maximization explains rightness, then rightness cannot explain happiness-maximization. But how can this be accommodated on Rosen's picture? Suppose, as utilitarians do, that the following holds:

REVERSE MODAL UTILITARIANISM: Necessarily, all right acts are happiness-maximizing.

How can we avoid the implication that happiness-maximization is explained by rightness together with this principle?

Here Rosen concedes that the second proposal mentioned above will not help, since reversed principles need not be less fundamental (2017: 154). He suggests however that asymmetry could be retained by appealing to the first proposal, according to which there is 
a list of potential right-makers built into the essence of normative properties (2017: 153-154). However, we have already seen how the list-suggestion is problematic in several ways. ${ }^{27}$

I conclude that a purely modal account of the normative laws fails to accommodate the formal properties of normative explanations, and so the Mackiean challenge must be dealt with in some other way.

\subsection{The Platonic Approach}

Skarsaune (2015) suggests that non-naturalists distinguish between two different kinds of normative properties: type-applying and token-applying. The type-applying properties are taken as primitive and basic, whereas the token-applying properties are analyzed in terms of

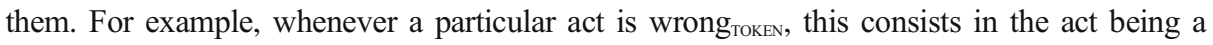
token of a wrong ${ }_{\text {TYPE }}$ action-type.

Skarsaune suggests that types have their normative properties necessarily, and so we get necessary normative principles in the form of action-types having type-applying normative properties. For example, we might get:

PLATONIC UTILITARIANISM: Necessarily, the action-type maximizing happiness is right $\mathrm{TYPE}_{\text {. }}$

Inserting this principle into the nomological model, particular acts being right ${ }_{\text {TOKEN }}$ will be explained by their maximizing happiness, together with PLATONIC UTILITARIANISM. ${ }^{28}$

This approach, too, would appear to demystify the non-naturalist's because-relation. As-

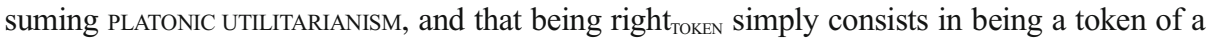
right $_{\mathrm{TYPE}}$ action-type, it does not seem so mysterious how happiness-maximization could (partly) explain sui generis rightness. Moreover, assuming a sufficiently fine-grained individuation of action-types, Skarsaune's account straightforwardly secures the formal properties of normative explanations. Hyperintensionality is secured, for example, since an action-type having a certain normative property does not imply that distinct but necessarily co-extensive action-types also have that property.

For all its ingenuity, however, the problem with Skarsaune's approach is that type-applying normative properties are hard to even make sense of. I don't understand what it means to say that an action-type has a normative property, unless this is just a convenient way of talking about its actual or possible tokens. While tokens of murder and torture are horrible, the actiontypes themselves appear utterly indifferent. There is nothing objectionable about torture, as long as no one is ever tortured! Thus, the wrongness of action-types wouldn't reflect badly on them. But wrongness is supposed to be a property that reflects badly on its bearer. Thus, I don't see how Skarsaune's type-applying wrongness is a kind of wrongness. To say that a certain action-type is wrong is like saying that a certain brain-type is conscious. We might put things that way for convenience, but it could not be literally true.

I conclude that Skarsaune's account gets things backwards. Insofar as we can intelligibly talk of type-applying normative properties, these must be defined in terms of the tokenapplying ones.

\footnotetext{
${ }^{27}$ Rosen also sketches a different way of accommodating asymmetry, but one that abandons a purely modal characterization of the normative laws (2017: §12). I will return to this suggestion in Section 5.3 below.

${ }^{28}$ As Skarsaune (2015: 268, n. 16) notes, Mackie anticipates something like this approach. Mackie's all too brief response is to ask "but what is this belonging of properties to other properties, and how can we discern it?" (1977: 41)
} 


\subsection{The Explanatory-Connection Approach}

In addition to the modal approach, Rosen outlines a different way of construing the normative laws (2017: §12). In view of some of the difficulties mentioned in Section 5.1 above, he suggests that non-naturalists might build an unanalyzed explanatory connection into the laws themselves. Rosen calls it "normative grounding." Again, he construes the connection as metaphysically contingent, which conflicts with my assumptions. I will thus take the idea to be that whenever a particular act has some sui generis normative property B, this is metaphysically explained by the act's having some natural property A, and it being metaphysically necessary that all A-acts are B-acts because they are A-acts. For example, we might get:

EXPLANATORY-CONNECTION UTILITARIANISM: Necessarily, all happiness-maximizing acts are right because they maximize happiness.

This approach does not quite fit with the nomological model as I have construed it, however. Call an act having a natural property A an "A-fact," and it having a sui generis normative property B a "B-fact." First, the explanatory content of the law cannot be that A-facts fully explain B-facts, since the model assumes otherwise. But the explanatory content cannot be that A-facts partially explain B-facts either, since that would be incomplete. And the explanatory content cannot be that A-facts together with the law fully explain B-facts, since that would make the content circular. $^{29}$

The approach does however fit nicely with a slightly modified version of the nomological model, on which A-facts fully explain B-facts, but where this, in turn, is fully explained by a normative law. On this modified model, then, normative laws do not combine with A-facts to explain B-facts. Rather, the laws fully explain why A-facts fully explain B-facts. ${ }^{30}$

By thus building explanatory content into the normative laws, this approach secures the formal properties of normative explanations. It also promises demystification, in that the explanatory relation between A-facts and B-facts will no longer be brute, and thus no longer within the reach of MODEST MACKIEAN.

Unsurprisingly, however, from a Mackiean point of view this just relocates the mystery to the normative laws themselves. If it was mysterious how A-facts could fully and necessarily explain B-facts, it will not help to say that a normative law makes it so. ${ }^{31}$ The problem is not that there is something inherently mysterious about metaphysical laws. That is a separate issue. The problem is rather that the explanans will ultimately have to involve a brute metaphysically necessary and fully explanatory relation between discontinuous

\footnotetext{
${ }^{29}$ Cf. Berker (2018).

${ }^{30}$ Berker (2018) calls the two models "Principles as Partial Grounds" and "Principles as Meta-Grounds," respectively.

${ }^{31}$ An analogy: Consider how lame it would be to posit psycho-physical laws to solve the hard problem of consciousness. If it was mysterious how physical properties could give rise to phenomenal properties, when these seem utterly different, it will be equally mysterious how there could be such laws. However, since phenomenal properties are plausibly explained by physical properties, the hard problem of consciousness may provide nonnaturalists with a valuable partner-in-guilt strategy.
} 
properties. Thus, the explanatory-connection approach will not help non-naturalists to steer clear of MODEST MACKIEAN. ${ }^{32}$

\section{Conclusion}

In this paper I have extracted a precise supervenience-related challenge from Mackie's discussion, and I have argued that this challenge, as embodied in the Mackiean argument, is more fundamental than the supervenience challenge as usually conceived. In a nutshell, the challenge for non-naturalists is to account for NORMATIVE EXPLANATION without mysterious commitments, or show that non-naturalism is otherwise attractive enough to compensate for such commitments. The nomological model promises to deal with the challenge in the first way. As we have seen, however, at least three different versions fail in this regard, and it is not clear how the model might be successfully modified. The difficulty is to accommodate the formal properties of normative explanations without simply relocating the mystery, and without running into even worse troubles. $^{33}$

Open Access This article is distributed under the terms of the Creative Commons Attribution 4.0 International License (http://creativecommons.org/licenses/by/4.0/), which permits unrestricted use, distribution, and reproduction in any medium, provided you give appropriate credit to the original author(s) and the source, provide a link to the Creative Commons license, and indicate if changes were made.

\footnotetext{
$\overline{32}$ For clarity, let me just mention two nearby issues which may be thought to affect the point about mysteryrelocation. First, there is an issue about how to understand the generality of normative laws. As we have seen, Rosen (2017) thinks of it in terms of quantification, and I have also put things that way. In contrast, Glazier (2016: §5) argues that even necessary universal generalizations are at least partially explained by their instances, and so on pain of circularity they cannot even partially explain those instances. Instead, he suggests that general metaphysically explanatory connections should be formulated using a new variable-binding operator: $<<$. Although Glazier does not discuss normative laws specifically, adopting his proposal will give us normative laws of the following form:
}

EXPLANATORY-CONNECTION UTILITARIANISM* ${ }^{*} x$ maximizes happiness $<<_{x} x$ is right.

This issue does not affect the Mackiean challenge, however, since normative laws understood Glazier-wise are no less mysterious. If anything, Glazier's novel operator would add a mystery. Cf. Berker (2018: 24).

Another issue arises due to Dasgupta's (2016) distinction between substantive and autonomous facts. While substantive facts may or may not require further explanation, autonomous facts are not apt for explanation in the first place. Among brute facts we can thus distinguish between the substantive ones, which may require further explanation, and the autonomous ones, concerning which the issue of further explanation does not even arise. Dasgupta points to facts about essences as candidate autonomous facts (2016: §4). To illustrate, certain facts about the position of an electron may have no explanation, but at least it makes sense to ask for one. By contrast, facts about what it is to be an electron may not be apt for explanation in this sense.

Again, the Mackiean challenge remains unaffected. Construing normative laws as autonomous may be well motivated for other reasons, but it will not make them appear any less mysterious.

${ }^{33}$ For helpful comments, I thank Lars Bergström, Gunnar Björnsson, Krister Bykvist, Erik Carlson, Nils Franzén, Jan Gertken, Anandi Hattiangadi, Jonas Olson, Andrew Reisner, Henrik Rydéhn, Mark Schroeder, Folke Tersman, and several anonymous referees. I am especially grateful to Karin Enflo, Jens Johansson, and Olle Risberg. 


\section{References}

Berker S (2018) The explanatory ambitions of moral principles. Noûs:1-33. https://doi.org/10.1111/nous.12246 Blackburn S (1971) Moral realism. In: Casey J (ed) Morality and moral reasoning. Methuen, London, pp 101-124 Bliss R, Trogdon K (2014) Metaphysical grounding. In: Zalta EN (ed) The Stanford Encyclopedia of Philosophy (Winter 2014 Edition), https://plato.stanford.edu/archives/win2014/entries/grounding/

Dasgupta S (2016) Metaphysical rationalism. Noûs 50:379-418

Enoch D (2011) Taking morality seriously: a defense of robust realism. Oxford University Press, Oxford

Glazier M (2016) Laws and the completeness of the fundamental. In: Jago M (ed) Reality making. Oxford University Press, Oxford, pp 11-37

Hattiangadi A (2018) Moral supervenience. Can J Philos 48:592-615

Huemer M (2005) Ethical intuitionism. Palgrave Macmillan, Basingstoke

Jackson F (1998) From metaphysics to ethics: a defence of conceptual analysis. Clarendon Press, Oxford

Leary S (2017) Non-naturalism and normative necessities. In: Shafer-Landau R (ed) Oxford studies in metaethics, vol 12. Oxford University Press, Oxford, pp 76-105

Mackie JL (1977) Ethics: inventing right and wrong. Penguin Books, Harmondsworth

Mackie JL (1982) The miracle of theism. Clarendon Press, Oxford

McLaughlin B, Bennett K (2018) Supervenience. In: Zalta EN (ed) The Stanford Encyclopedia of Philosophy (Winter 2018 Edition), https://plato.stanford.edu/archives/win2018/entries/supervenience/

McPherson T (2012) Ethical non-naturalism and the metaphysics of supervenience. In: Shafer-Landau R (ed) Oxford studies in metaethics, vol 7. Oxford University Press, Oxford, pp 205-234

Moberger V (2018) The queerness of objective values: an essay on Mackiean metaethics and the arguments from queerness. Dissertation, Uppsala University

Olson J (2014) Moral error theory: history, critique, defence. Oxford University Press, Oxford

Parfit D (2011) On what matters, vol 2. Oxford University Press, Oxford

Rosen G (2017) What is a moral law? In: Shafer-Landau R (ed) Oxford studies in metaethics, vol 12. Oxford University Press, Oxford, pp 135-159

Rosen G (forthcoming) Normative necessity. In: Dumitru M (ed) Metaphysics, meaning, and modality: Themes from Kit Fine. Oxford University Press, Oxford

Schroeder M (2007) Slaves of the passions. Oxford University Press, Oxford

Shafer-Landau R (2003) Moral realism: a defence. Clarendon Press, Oxford

Skarsaune KO (2015) How to be a moral Platonist. In: Shafer-Landau R (ed) Oxford studies in metaethics, vol 10. Oxford University Press, Oxford, pp 245-272

Väyrynen P (2013) Grounding and normative explanation. Proc Aristot Soc 87(Suppl):155-178

Väyrynen P (2017) The supervenience challenge to non-naturalism. In: McPherson T, Plunkett D (eds) The Routledge handbook of metaethics. Routledge, London, pp 170-184

Publisher's Note Springer Nature remains neutral with regard to jurisdictional claims in published maps and institutional affiliations. 